\title{
STRAin RATE AND MATERIAL StATE INFLUENCE ON THE DEFORMATION RESISTANCE OF SOME TOOL STEELS
}

\author{
Chelu, G.; Ghiban, N.; SABAn, R.; Ghiban, B. \& SERBAn, N.
}

Abstract: This paper presents the results of the experimental researches conducted in order to establish the deformation resistance for some low and medium alloyed tool steels, used for the forging process of metallic materials, dependent on the strain rate and on the material state (cast or initially plastically formed).

Key words: deformation resistance, tool steel, plastically deformation degree, strain rate
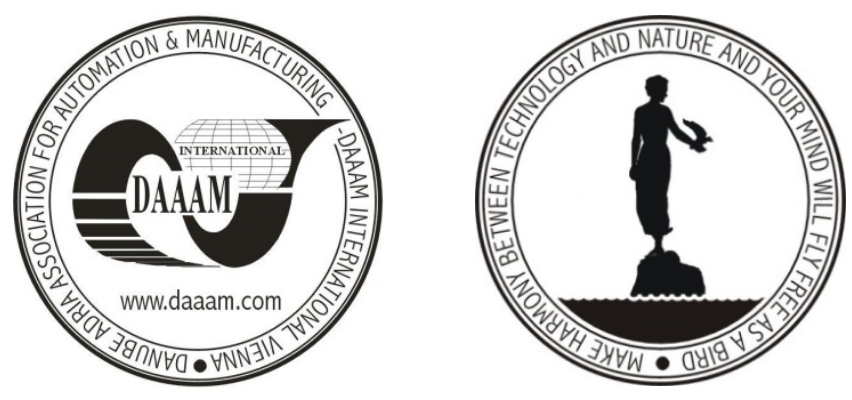

Authors' data: Chelu, G[heorghe]; Ghiban, N[icolae]; Saban, R[ami]; Prof. Dr.Eng Ghiban, B[randusa]; Serban, N[icolae], University Politehnica Bucharest Splaiul Independentei 313, 7000, Bucharest, RO, gchelu@email.ro, ghibanbrandusa@yahoo.com, nicolaeghiban@yahoo.com, ramisaban@yahoo.com, schneider_nicu@yahoo.com

This Publication has to be referred as: Chelu, G[heorghe]; Ghiban, N[icolae]; Saban, R[ami]; Ghiban, B[randusa] \& Serban, N[icolae] (2008). Strain Rate and Material State Influence on the Deformation Resistance of Some Tool Steels, Chapter 19 in DAAAM International Scientific Book 2008, pp. 219-228, B. Katalinic (Ed.), Published by DAAAM International, ISBN 978-3-901509-66-7, ISSN 1726-9687, Vienna, Austria DOI: 10.2507/daaam.scibook.2008.19 